\title{
TRADUÇÃO DE VIDEOGAMES: TODO O PODER AO TRADUTOR
}

Michel Teixeira*

\section{Introdução}

No campo da tradução de videogames ${ }^{1}$, a atuação de tradutores, no papel de mediadores culturais, e de jogadores, na condição de público consumidor propenso a vocalizar opiniões favoráveis ou contrárias, pode ser decisiva para o formato final do produto lançado, para seu sucesso de vendas e até mesmo para as futuras versões do game. Neste artigo, analisamos as características da localização de videogames enquanto produtos multilíngues, os desafios específicos apresentados para sua tradução e o papel de tradutores e jogadores no produto final.

Em primeiro lugar, é preciso entender a magnitude do mercado de videogames hoje em dia. Segundo relatório da consultoria Newzoo (2016), a previsão era de que os jogos eletrônicos - oferecidos em consoles, computadores e dispositivos móveis - obtivessem uma receita de 99,6 bilhões de dólares em todo o mundo em 2016, uma estimativa de crescimento de 8,5\% em relação a 2015. Na América Latina, o faturamento previsto era de 4,1 bilhões de dólares, em um crescimento considerável de 20,1\%. Para o Brasil, a Newzoo (2017) estimou uma receita de 1,5 bilhão de dólares para um total de 61,2 milhões de jogadores em 2017.

\footnotetext{
* Mestrando do Programa de Pós-Graduação em Estudos da Linguagem (PPGEL) da PUC-Rio.

${ }^{1}$ Os termos videogame, game e jogo serão usados de maneira intercambiável neste artigo, sempre no sentido de "jogo em que se manipulam eletronicamente imagens numa tela de televisão" (Dicionário eletrônico Houaiss de língua portuguesa, 2009.3). A grafia adotada é a reconhecida pelo Vocabulário Ortográfico da Língua Portuguesa, editado pela Academia Brasileira de Letras.
} 
A expansão do mercado de games nas últimas décadas está diretamente ligada ao desenvolvimento de novas tecnologias da informação. O desenvolvimento de recursos mais sofisticados em termos de processamento, resolução gráfica, armazenamento e plataformas, dentre outros, permitiu o desenvolvimento de games com narrativas aprimoradas e situações de jogo mais complexas que as oferecidas anteriormente, atraindo a atenção de um público mais adulto. Para se ter um parâmetro, hoje, a idade média entre os 155 milhões de jogadores nos Estados Unidos é de 35 anos (ESA, 2015).

Os novos recursos tecnológicos permitiram, também, que os videogames passassem a oferecer ao jogador a opção de escolher um entre diversos idiomas dentro da plataforma de jogo. No caso de um MMORPG (Massively Multiplayer Online Role-Playing Game; jogo de interpretação de personagens online multijogador em massa), que combina o mecanismo de RPG, um tipo de jogo em que o jogador assume o papel de um personagem e participa ativamente do ambiente em que a história é desenvolvida, a uma plataforma online para um grande número de jogadores que interagem em tempo real, a maior facilidade de inserir novos idiomas trouxe novas oportunidades de ampliação de mercado, como a possibilidade de atingir uma maior faixa de públicos não falantes do inglês.

Via de regra, os MMORPG envolvem histórias complexas, que demandam, por exemplo, a leitura de missões a serem cumpridas pelos personagens dos jogadores, instruções sobre como proceder em determinadas situações de jogo e interações, por meio de diálogos, entre o jogador e os personagens internos do game. A tradução para jogos com essas características para o maior número possível de idiomas representa um aumento significativo do público-alvo a ser atingido pelo produto.

\section{Localização}

Por suas características particulares, a tradução de games é considerada um processo de localização. Segundo a LISA (Localization Industry Standards Association; Associação de Padrões da Indústria de Localização), "localização é tornar um produto linguística e culturalmente adequado ao locale (país/região e língua) onde será usado e vendido" (Esselink, apud Costa e Silva, 2014, p. 95). Bernal-Merino (2007, p. 2) ressalta que "os tradutores envolvidos na 
localização de jogos precisam lidar com uma mistura de desafios muito particular" ${ }^{\prime 2}$. Neste trabalho, usamos como referência a tabela de etapas do processo de localização de games apresentada por Souza (2015, p. 29), a saber: (i) preparação; (ii) planejamento; (iii) extração dos textos a serem traduzidos; (iv) tradução; (v) gravação do áudio traduzido, quando houver; (vi) integração do áudio (se houver) e dos textos traduzidos ao software do jogo; e (vii) teste para garantia de qualidade.

Ressalte-se, porém, que essas etapas não são necessariamente seguidas em todos os projetos de localização de games. Pelo contrário, muitas vezes os passos necessários são negligenciados por razões de prazo e orçamento. Neste trabalho, para fins de ilustração, descrevemos cada uma das etapas mencionadas acima, para que o leitor possa ter uma visão geral do processo como um todo, da maneira como costuma ocorrer com os games de maior potencial de vendas.

\subsection{Etapas}

De início, o desenvolvedor do game precisa "preparar o software do jogo para acomodar versões localizadas para o maior número de idiomas possíveis" (Souza, 2015, p. 29). A segunda etapa é o planejamento do processo de localização, que inclui a elaboração do orçamento e a definição dos prazos de produção até o lançamento. A localização do game geralmente segue um dos modelos a seguir: i) sim-ship, ou lançamento simultâneo, em que o produto original e suas versões localizadas são publicados ao mesmo tempo; ou ii) localização pós-lançamento do game. Mangiron e O’Hagan (2013, p. 72) ressaltam que tradutores "que trabalham com o modelo sim-ship estão propensos a terem o desafio adicional de realizar sua tarefa sem poder ver - ou jogar - a versão final do jogo".

Em seguida, vêm a extração e a importação do texto para formatos que possam ser processados por ferramentas de tradução assistida por computador. Essa etapa é essencial para o projeto de localização como um todo, já que essas ferramentas permitem o compartilhamento não só dos arquivos de tradução entre vários tradutores, mas também de glossários e bancos de

\footnotetext{
2 São nossas todas as traduções para o português de textos publicados em língua estrangeira (cf. Bibliografia).
} 
dados bilíngues. Esses bancos de dados, chamados memórias de tradução, armazenam as traduções já realizadas, que servirão de base de comparação e referência para as novas traduções a serem feitas pela equipe.

Após a preparação, inicia-se a tradução. Nesse ponto, a localização de games começa a se diferenciar de outros processos de localização, como de páginas da internet ou aplicativos para dispositivos móveis, por exemplo, que envolvem, respectivamente, apenas o conteúdo online ou do software propriamente dito. A localização de games pode abranger não só o conteúdo in-game, ou seja, que aparece enquanto o usuário está efetivamente jogando, como legendas, textos para dublagem e artes do jogo contendo palavras, mas também outros elementos da interface de usuário, como botões e rótulos do menu de navegação, contratos de licença de usuário final, termos de uso e serviço, arquivos de ajuda e suporte e manuais. Além disso, no caso de produtos com grande potencial de vendas, o processo de localização pode envolver também sites oficiais, blogs oficiais, embalagens, material publicitário e de marketing, entre outros. De acordo com o tamanho e as características do projeto, o tradutor ou equipe de tradutores terá de lidar com um, alguns ou todos os tipos de textos citados acima.

As duas etapas que se seguem à tradução dos textos geralmente são executadas por outros profissionais contratados pela empresa de serviços linguísticos responsável pelo projeto, embora já existam empresas que ofereçam o pacote de localização completo. As etapas são: (i) dublagem dos textos por atores profissionais, comandados por um diretor de dublagem, nos jogos que envolvem textos falados, e (ii) integração de arquivos de dublagem e legendas (se houver), bem como dos textos traduzidos ao software, uma etapa cumprida por especialistas em programação, geralmente contratados pelo próprio desenvolvedor do game.

A última etapa antes do lançamento, para jogos que cumprem o ciclo completo de localização, é chamada de QA (quality assurance: "garantia de qualidade") e envolve testes para determinar se os elementos da tradução se encaixam no contexto do game enquanto ele é jogado. 


\subsection{Desafios}

A garantia de qualidade é essencial para corrigir falhas decorrentes de um dos problemas reconhecidamente mais comuns do mercado de tradução de games: a falta de tempo e planejamento para execução do projeto de localização. O tradutor alemão Frank Dietz usou sua experiência nesse mercado para descrever melhor o que acontece:

Na raiz de muitos problemas relacionados à localização de games está o fato
de que um lançamento simultâneo (ou quase simultâneo) de versões em
vários idiomas requer um desenvolvimento paralelo. Programadores, de-
signers, técnicos de som e artistas gráficos que normalmente já estão nos
últimos estágios do desenvolvimento do jogo também precisam dedicar
parte do tempo para criar (e corrigir) versões em línguas estrangeiras. Do
lado do tradutor, o desenvolvimento paralelo significa trabalhar em um
texto que, apesar de todas as garantias em contrário, ainda não foi finali-
zado, e muitas vezes exige reescrita e retradução em ritmo frenético ao
longo dos últimos dias antes da chegada do game ao mercado (Dietz, 2007,
p. 4).

Em mesa-redonda sobre tradução de games no VII Congresso Internacional de Tradução e Interpretação da ABRATES (Associação Brasileira de Tradutores), realizada no dia 4 de junho de 2016 no Rio de Janeiro, uma das palestrantes, a tradutora Paula Ianelli, corroborou as palavras de Dietz ao discorrer sobre sua experiência na localização de games para o mercado brasileiro. Disse ela:

Muitas vezes o tradutor recebe arquivos de tradução sem qualquer referência do que se refere a quê. Em um jogo, havia a tradução do termo "ring", assim, solto em um arquivo Excel, sem nenhum contexto. Foi usada, por absoluta falta de referência, a palavra "anel". Quando o game ficou pronto, a palavra anel apareceu ao lado de um sino na tela. Ring deveria ser traduzido como verbo: tocar o sino (informação verbal) ${ }^{3}$.

Ao admitir que uma parte dos projetos de desenvolvimento de games é mal gerenciada, o que gera atrasos e gastos excessivos, Dietz (2007, p. 4) acrescenta que, para ele, "a localização só é pensada no último instante e costuma ser gerenciada por alguém que não tem experiência na área".

\footnotetext{
${ }^{3}$ Mesa-redonda sobre localização de jogos. VII Congresso Internacional de Tradução e Interpretação da ABRATES.
} 


\subsection{Expectativas}

Para Bernal-Merino (2008, p. 62), o texto localizado "é o original em outros idiomas, e os jogadores, seja qual for sua cultura, devem experimentá-lo como original". Assim, o objetivo final de uma localização bem-sucedida é permitir que os jogadores façam uma imersão na experiência de jogo e nas atividades relacionadas a vencê-lo, sem ser distraídos por problemas prosaicos como má tradução, textos truncados, codificação de caracteres ou interface de usuário ilegível" (p. 65).

A despeito de condições de trabalho favoráveis ou desfavoráveis, a expectativa em torno do trabalho do tradutor de games costuma ser muito alta, principalmente por se tratar de um produto que precisa gerar um rápido retorno sobre o investimento. Ao contrário da maioria dos bens culturais, os games sofrem uma depreciação de preço significativa em poucos meses, que pode chegar a apenas uma fração de seu valor original após um ano ${ }^{4}$.

O que se busca é desenvolver um produto que seja atraente para o público e consiga gerar um boca-a-boca favorável em pouco tempo. Note-se que, ao falarmos de boca-a-boca, estamos nos referindo também a discussões em fóruns e comunidades virtuais, em blogs e redes sociais, o que amplifica consideravelmente o efeito, positivo ou negativo, de críticas. No caso específico do Brasil, uma localização bem-sucedida, que recebe boas avaliações do público jogador, pode garantir "um aumento de $30 \%$ na receita de um jogo", afirmou André Faure (informação verbal) ${ }^{5}$, consultor na área de games, na mesa-redonda acima citada.

\section{Características da tradução de videogames}

Os profissionais de localização, na visão de Bernal-Merino, se valem da criatividade linguística para criar uma ponte entre culturas, que abre caminho para atender às preferências e expectativas dos jogadores de cada locale, ou seja, às características da língua e do país a que se destina o produto. $\mathrm{Na}$ localização de games, como na tradução literária, o tradutor assume o papel

\footnotetext{
4 Tome-se como exemplo o jogo FIFA para o console Playstation 4, que traz versões atualizadas todos os anos. No site de varejo www.americanas.com.br, acessado em 25 de agosto de 2016, o FIFA 16 custa R\$ 99,00, ao passo que as versões 15 e 14 custam $\mathrm{R} \$ 49,99$ e $\mathrm{R} \$ 49,89$, respectivamente. Note-se que, segundo o mesmo site, o valor original do FIFA 16, lançado em 22 de setembro de 2015, era de R\$ 249,90.

${ }^{5}$ Mesa-redonda sobre localização de jogos. VII Congresso Internacional de Tradução e Interpretação da ABRATES.
} 
de mediador cultural, operando "como alguém permanentemente em trânsito, situando-se nas margens das línguas e das culturas" (Marques, 2016, p. 208), na medida em que seu objetivo é permitir que o leitor/jogador tenha "a capacidade lidar com diferentes códigos, de experimentar diferentes papéis sociais" (idem).

Nos games, porém, a tradução precisa dar conta de uma exacerbação das tensões e estranhezas, descontinuidades e desajustes do encontro entre culturas, na medida em que, muitas vezes, a ação não se passa em um local específico, mas fantasioso, em que as fronteiras convencionais do nosso mundo não se aplicam, e em que o jogador, ao contrário do leitor, tem papel ativo na construção do mundo da fantasia. Muitas vezes, por questões mercadológicas, mesmo em jogos que tenham algum caráter ou inspiração histórica real, os mundos criados são uma adaptação da realidade, em que regiões, países e personagens têm suas características alteradas.

A localização de videogames tem, também, características semelhantes às de outras traduções de natureza polissemiótica, ou seja, em que "há outros canais (ou signos) envolvidos na comunicação, que tanto podem dificultá-la quanto facilitá-la" (Martinez, 2007, p. 14), tais como música e efeitos sonoros, letreiros e fluxo de imagens.

Bernal-Merino cita os seguintes exemplos de traduções polissemióticas cujas características são semelhantes às da localização de games: (i) localização de software: o conteúdo é de natureza técnica e funcional, além disso, por questões de espaço, a tradução precisa ser concisa; (ii) tradução audiovisual: o tradutor precisa manter a oralidade dos diálogos, tanto para dublagem quanto para legendagem; (iii) tradução de livros infantis: o texto precisa ser lúdico, divertido e cativante para capturar a atenção do leitor.

\section{Caso de localização de games: World of Warcraft}

A tradução para o português de World of Warcraft (WoW), um dos jogos mais bem-sucedidos da história, é um bom exemplo de processo de localização que contempla todos os passos necessários para entrega de um produto de qualidade, que atende às expectativas do mercado. O projeto, que durou mais de dois anos, reuniu uma equipe com dedicação exclusiva, composta de mais de duas dezenas de profissionais, entre lead linguists - responsáveis, 
por exemplo, pela elaboração do guia de estilo e pelas principais decisões relacionadas à tradução - tradutores, revisores, testadores e gerentes de projeto, dentre outros. Esse é um modelo mais condizente com um mercado que, como vimos, só no Brasil fatura mais de um bilhão de dólares por ano. Foi adotado para um jogo que "tem hoje 7,6 milhões de jogadores [em todo o mundo]", feito para "uma base de fãs que jogava em inglês" e somou "mais de quatro milhões de palavras e centenas de horas de áudio" (Costa e Silva, 2014, p. 97).

Costa e Silva ressalta que, a despeito da opinião expressa por jogadores brasileiros em fóruns e comunidades de que o inglês seria a língua original do jogo, ele é uma "representação da 'língua comum' [...], que fazia o papel de koiné, ou seja, língua franca" (Costa e Silva, 2014, p. 105). Essa língua comum é entendida por todas as raças que estão à disposição do jogador no jogo; porém, cada uma tem sua forma própria de expressão, em representações estilizadas do que seria o inglês de distintos grupos populacionais em várias partes do mundo. Dito de outra forma, as variações do inglês no jogo não refletem de forma estrita a realidade, são um simulacro. O mesmo acontece na localização brasileira, que adaptou elementos de grupos distintos no falar das raças, embora muitos jogadores tenham "identificado os dialetos e os associado a estereótipos de seu imaginário" (Costa e Silva, 2014, p. 111). Assim, a localização conseguiu estabelecer uma ponte com o real, como no jogo original, e a mediação cultural entre duas culturas de representação, não reais, foi bem-sucedida, pois não causou estranhamento, mas reconhecimento.

No WoW, vários elementos/personagens têm nomes que contraem duas palavras em inglês (chamados de "lego" pela equipe brasileira de localização, em referência ao famoso brinquedo de montar, pela característica de simplesmente juntar duas palavras em uma só). Nesse caso, o desafio era criar correspondentes que soassem bem a ouvidos brasileiros para personagens como Sylvanas Windrunner (Sylvana Correventos), Kael'thas Sunstrider (Kael'thas Andassol), Tyrande Whisperwind (Tyrande Murmuréolo) e Shandris Feathermoon (Shandris Plumaluna). Note-se que, nos dois últimos casos, recorreu-se a formas derivadas do latim, éolo e luna, para se referir ao 
vento e à lua, pois, no entender da equipe de lead linguists do jogo, essas formas nos soam mais familiares do que a contração inglesa.

Outro exemplo de tradução criativa bem-sucedida no WoW foi o contexto do personagem Hemet Nesingwary, inspirado no escritor norte-americano Ernest Hemingway. Havia livros, diálogos e situações de jogo relacionadas a Nesingwary que se inspiravam na vida e na obra de Hemingway. Para fugir ao risco de opacidade, a localização brasileira transformou o personagem em Rosarães Guima, inspirado em Guimarães Rosa, cujo discurso emulava a obra Grande sertão: veredas. Além disso, adaptou topônimos, nomes de personagens e situações para contextos que fizessem referência ao universo sertanejo do escritor brasileiro. Vemos então, mais um exemplo em que "o etnocentrismo e a domesticação são o caminho [para] fazer com que variantes linguísticas e referências culturais alcancem", para o jogador brasileiro, "a mesma função que tinham no jogo original" (Costa e Silva, 2014, p. 104).

\section{O poder dos tradutores de games}

Para obter resultados como os elencados acima, a localização de games exige um tradutor criativo, familiarizado com a tecnologia, apto a trabalhar sob pressão, com prazos curtos e, acima de tudo, que tenha capacidade de adaptar culturalmente os conteúdos à sua língua nativa de forma atraente. Não dar o devido valor ao domínio da redação em língua nativa é um equívoco que as empresas fornecedoras de serviços linguísticos costumam cometer com frequência. Essas empresas tendem a procurar profissionais que conheçam jogos muito bem, que joguem com frequência e que, idealmente, estejam imersos na cultura gamer - um discurso repetido de forma consistente pela indústria de localização de games.

Consideramos importante que os tradutores tenham a oportunidade de jogar os videogames que estão localizando, estejam familiarizados com o jargão da área e tenham conhecimentos de informática para lidar com os softwares usados no processo de localização. Faz-se necessário, porém, em nossa opinião, o contraponto de um tradutor que consiga "não só traduzir, mas transcriar", que tenha "precisão e criatividade" e valorize o "poder criativo" (Bernal-Merino, 2008, p. 57). 
Tradutores que tenham uma ampla formação geral, conheçam cultura popular e, especificamente, tenham interesse em literatura e bom domínio da escrita em sua língua nativa estão, em nossa visão, aptos a enfrentar os tantos desafios citados ao longo deste artigo, tais como manter o look and feel do texto original - ou seja, as imagens textuais e os sentimentos e sensações que o texto original causa no jogador. Além disso, que tenham repertório para fazer adaptações culturais consistentes como, por exemplo, adaptar nomes de personagens, lugares e objetos do game e ferramental para reconhecer a necessidade de adaptar quando for preciso, parafrasear quando for preciso, explicar quando for preciso, até omitir quando for preciso. Em suma, sejam capazes de "produzir um texto empolgante que se encaixa perfeitamente no jogo e aprimora a experiência dos jogadores em seu idioma e sua cultura" (Bernal-Merino, 2008, p. 64).

O mercado de localização de games precisa de tradutores que sejam agentes ativos na produção da obra. Essa posição ativa é tornada possível, na maioria dos projetos, por uma ferramenta que pode ser decisiva para o aprimoramento de uma tradução: a query sheet, ou folha de consultas. A query sheet é o instrumento oferecido para que tradutores e linguistas esclareçam dúvidas diretamente com o cliente. As dúvidas e questões apresentadas pelos profissionais de localização de games permitem aos desenvolvedores corrigir erros, fazer adaptações e, em determinados casos, produzir material que melhore o produto final graças aos inputs da equipe de tradução.

Nas palavras de Richard Honeywood, diretor de localização da Square Enix, uma das maiores empresas de desenvolvimento de games:

Às vezes os desenvolvedores ficam tão impressionados com as alterações feitas à versão traduzida que nos fornecem informações extras ou adicionam mais cenas ao jogo para aprimorar a apresentação das mudanças. É como se estivéssemos planejando a jogabilidade juntos ao traduzir (Honeywood, apud Bernal-Merino, 2008, p. 64).

\section{O poder dos jogadores}

É importante ressaltar que gamers são, via de regra, muito ativos na internet, e isso se reflete não só no boca-a-boca relacionado à avaliação de determinado jogo, mas também, por exemplo, em iniciativas como o crowdsourcing 
para financiar a produção de um projeto de game ou o trabalho dos fansubbers, que criam legendas não só para séries e filmes, mas, hoje, também para games.

Bernal-Merino cita um caso muito relevante ocorrido na Espanha com relação à dublagem em espanhol do jogo Age of Pirates: Caribbean Tales. O jogo foi considerado muito divertido pela comunidade de jogadores, e não houve muitos questionamentos em relação à qualidade da tradução, mas o trabalho dos dubladores foi "tão amador que um grupo de amadores decidiu se juntar e produzir um novo patch para aprimorar a versão oficial" (BernalMerino, 2008, p. 60). Patches são arquivos de atualização de jogo e, geralmente, ficam disponíveis para download. Nesse caso específico, o patch substituiu a fala oficial do jogo pelo trabalho dos dubladores amadores.

\section{Considerações finais}

Por suas características de produto cultural voltado para um público global falante de uma grande variedade de idiomas, com retorno sobre investimento imediato e desvalorização relativamente rápida, os videogames exigem uma tradução de qualidade e concentrada na cultura do público-alvo. Esse público consumidor é formado por jogadores que, por sua vez, demandam alto nível de qualidade na interação com o jogo e não se furtam a discutir o game na internet, produzindo conteúdo crítico que pode ser decisivo para o sucesso do produto. Por tudo isso, tradutores e jogadores exercem sobre o game um poder que não tem equivalente em relação a outros bens culturais. Este é um campo que merece mais estudos e novos olhares para entender a nova economia digital que gera lucros consideráveis no mercado mundial.

\section{Referências bibliográficas}

BERNAL-MERINO, Miguel Á. "Challenges in the translation of video games". Revista Tradumática, n. 5, nov. 2007. Disponível em: http://www.fti.uab.cat/tradumatica/revista/num5/articles/02/02.pdf BERNAL-MERINO, Miguel Á. "Creativity in the translation of video games". Quaderns de Filologia. Estudis literaris, v. XIII, p. 57-70, 2008. 
ESA - Entertainment Software Association. "Sales, Demographic and Usage Data. Essential Facts About the Computer and Video Game Industry". 2015. Disponível em:

http://www.theesa.com/wp-content/uploads/2015/04/ESA-Essential-Facts2015.pdf (acesso em 19 de junho de 2017)

NEWZOO. “The Brazilian Gamer 2017”. 2017. Disponível em:

https://newzoo.com/insights/countries/brazil/ (acesso em 19 de junho de 2017)

NEWZOO. “Global Games Market Report 2016”. 2016. Disponível em:

http://resources.newzoo.com/global-games-market-report (acesso em 19 de junho de 2017)

COSTA E SILVA, Heber. "Variedades linguísticas na localização de games: dialetos e raças do World of Warcraft". Scientia Traductionis, n. 15, p. 94-117, dez. 2014, Florianópolis.

DIETZ, Frank. "“How difficult can that be?" - The work of computer and video game localization". Revista Tradumática, n. 5, nov. 2007. Disponível em:

http://www.fti.uab.es/tradumatica/revista/num5/articles/04/04.pdf

MANGIRON, Carmen; O'HAGAN, Minako. “Localização de jogos: libertando a imaginação com tradução "restrita"”". In-Traduções, v. 5, n. esp.- Games e Tradução, p. 68-85, out. 2013, Florianópolis.

MARQUES, Reinaldo. "Henriqueta Lisboa: tradução e mediação cultural". Scripta, p. 202-212, jul. 2016. Disponível em: http://200.229.32.55/index.php/scripta/article/view/12580/9879 (acesso em 17 de fevereiro de 2017)

MARTINEZ, Sabrina. “Tradução para legendas: uma proposta para a formação de profissionais". Dissertação (Mestrado em Letras) - Pontifícia Universidade Católica do Rio de Janeiro, Rio de Janeiro, 2007.

SOUZA, Ricardo Vinícius. "Tradução e videogames: uma perspectiva histórico-descritiva sobre a localização de games no Brasil". Dissertação (Mestrado em Letras) - Departamento de Letras Modernas da Faculdade de Filosofia, Letras e Ciências Humanas. São Paulo: Universidade de São Paulo, 2015. 


\title{
Resumo
}

Este artigo apresenta distintos aspectos da localização de videogames, destacando a influência do público consumidor e, principalmente, do tradutor no produto final traduzido para outro idioma. São abordados o mercado atual de videogames, as etapas e as características específicas do processo de localização como um todo. Analisamos as especificidades do trabalho e da formação do tradutor e a importância da adaptação cultural para o sucesso de um videogame em termos de vendas e aceitação do público consumidor.

\begin{abstract}
This paper presents different aspects of videogame localization, specially the influence of customers and, above all, the translator in the translated product. It discusses the current videogame market, the steps and specific features of the videogame localization process as a whole. The specificities of a translator's work and background, as well as the importance of cultural adaptation, are analysed as key factors for a successful game both in sales and customer acceptance.
\end{abstract}

